\title{
High-Temperature Ductile Damage Behavior and Modeling of X100 Pipeline Steel
}

\author{
Lifeng Fan ${ }^{1}$, Ge Wang ${ }^{2}$, Pei Liang ${ }^{2}$, Jing $\mathrm{Ma}^{3}$, Qunqun Bao ${ }^{4}$ and Hong Zhang ${ }^{1, *}$ \\ ${ }^{1}$ Inner Mongolia Engineering Research Center for Urban Transportation Data Science and Applications, Inner Mongolia University, \\ Hohhot 010070, China \\ ${ }^{2}$ National Engineering Research Center for Equipment and Technology of Cold Strip Rolling, Yanshan University, Qinhuangdao 066004, \\ China \\ ${ }^{3}$ College of Material Science and Engineering, Hebei University of Science and Technology, Shijiazhuang 050018, China \\ ${ }^{4}$ Inner Mongolia High-Grade Highway Construction and Development CO., LTD, Hohhot 010051, China
}

Received 5 March 2019; Accepted 25 May 2019

\begin{abstract}
Induction heat-bended pipes used in oil and gas pipelines are commonly manufactured by heating-bending techniques, and ductile fractures related to large deformation easily occur in the heating-bending manufacturing process. This study investigated the ductile damage behavior and modeling of X100 pipeline steel to reveal the evolution of ductile damage fracture of high-strength pipeline steel at high temperatures. Three methods, namely, Gleeble tensile, separation Hopkinson pressure bar (SHPB), and MTS quasi-static notch tensile tests, were performed at room and high temperatures for the analysis of the characteristics of flow stress and failure strain of X100 pipeline steel. The Johnson-Cook model was used for the establishment of the damage constitutive model of X100 pipeline steel, and its accuracy and reliability were verified by experimental data. Results show that strain rate enhancement and high-temperature softening effect are significant. The failure strain of X100 pipeline steel is positively correlated with temperature and negatively correlated with stress triaxiality and strain rate. The established constitutive model can accurately describe the high-temperature plastic deformation and damage evolution behavior of X100 pipeline steel. This study provides a foundation for the prediction of damage and failure in heating-bending process.
\end{abstract}

Keywords: X100 pipeline steel, Damage failure, Johnson-Cook model, Finite element analysis

\section{Introduction}

The growing energy demand in different areas of the world and the distance between gas reservoirs and consumers has increased the need to transport gas from far away regions to the final market. Distant gas transportation is achieved with pipelines, which has the advantages of economy, safety, and long-distance uninterrupted transportation and is especially suitable for oil and natural gas transportation. Oil and gas pipelines with large diameters, thick walls, and high strengths are developed to reduce transportation costs and increase transportation pressure. Induction heat-bended pipes used in oil and gas pipelines are commonly manufactured through heating-bending, during which ductile fractures related to large deformation easily occur, especially under the action of high temperature and large deformation. Defects related to plastic damage and pipeline steel fracture have increased, which seriously threaten the quality of pipeline products. Various research institutions have constantly focused on the development of pipeline steels, and new high-strength pipeline steel, such as X100 pipeline steel, have been continuously developed and applied. X100 pipeline steel has high strength and high toughness characteristics [1], but its plastic deformation and damage failure behavior should be investigated. To solve these problems, R. Ghajar, F. Lob, and Tanguy B. et al.

*E-mail address: ysufanlifeng@foxmail.com

ISSN: $1791-2377 @ 2019$ Eastern Macedonia and Thrace Institute of Technology. All rights reserved.

doi:10.25103/jestr.122.22 investigated the effects of anisotropic, stress triaxiality, and Lode angle on plastic damage of X100 pipeline steel. Although these results were obtained at room temperature state, the effects of temperature and strain rate on plastic deformation and damage were not considered and thus heating-bending was limitedly applied. This study is concerned with the problems in the high-temperature plastic damage constitutive model of X100 high-grade pipeline steel. The mechanical properties and damage fracture behavior of X100 pipeline steel were investigated by performing separation Hopkinson pressure bar (SHPB) damage mechanics test, Gleeble damage mechanics test, and quasistatic tensile test on a notched specimen. A damage constitutive model of X100 pipeline steel based on JohnsonCook (JC) model was established and verified by experimental data. The results provided a foundation for X100 pipeline damage and failure mechanisms and designed a method for heating-bending parameters.

\section{State-of-the-art}

A considerable number of studies on plastic damage fracture in pipeline steel have been conducted. Previous studies focused on brittle fracture in pipeline steel, using the fracture criterion with CVN as parameter and DWTT test requirement established by Battelle, which ensure the operation above the temperature of ductile-brittle transition temperature and effectively prevent the occurrence of brittle fracture. 
In the 1970s, ductile fracture initiation and crack arrest attracted considerable attention owing to the discovery of long-range ductile crack propagation; accordingly, Battelle and AISI conducted a large number of full-scale blasting experiments [3]. Oh CK [4] et al. proposed a ductile fracture criterion of X65. With the improvement of pipeline steel material grade, full-scale blasting test results have shown that the crack arrest toughness calculated by traditional empirical formula cannot effectively guarantee the safety crack arrest of steel pipes. High-grade pipeline steel has good plasticity and toughness, which make plastic damage occupy the majority of service life of pipeline steel. In the past 20 years, the plastic damage behavior of pipeline steel has attracted considerable attention. The plastic damage mechanism of X65 pipeline steel (ferrite type) was investigated by Qiu [5]. The separation of $\mathrm{Ca}$ inclusion and matrix interface is the main factor of pore initiation. Poruks [6] observed that the separation of martensite and matrix interface is the main factor of pore initiation in low-carbon bainitic steel. Qiu [7] clarified the mechanism of calciumtreated sulfide and MA island initiation voids in X80 steel and determined the bonding strength of calcium-treated sulfides and MA islands with the matrix in X80 steel through tensile test.

Numerous studies showed that inclusions or secondphase particles are the main cause of microcavity initiation. However, the mechanism of plastic damage initiation of pipeline steel remains unclear. A plastic damage model for quantitatively evaluating the plastic damage evolution mechanism of pipeline steel is urgently needed. Some studies assessed the damage and fracture behavior of pipeline steel through numerical calculation and experiment [8-12]. Rahmatollah Ghajar [13] et al. investigated the effect of anisotropy, triaxiality factor, and Lode angle on failure. F. Iob [14] et al. provided a model with 3D description of anisotropic behavior to represent ductile hardening in all directions up to fracture. Tanguy B. [15] et al. developed a constitutive model by integrating anisotropic behavior and ductile damage in X100 pipeline steel. Yang Li[16] et al. studied the effects of constraint on ductile crack growth behavior to evaluate the anisotropy of X100 pipeline steel. G. Mirone[17] et al. implemented four-failure models, where
Bao-Wierzbicki response to triaxiality was coupled to different Lode angle sensitivities.

In summary, the effects of anisotropy, triaxial stress, and Lode angle on the plastic damage behavior of X100 pipeline steel are analyzed, and the effects of high temperature and high strain rate on plastic damage behavior of X100 pipeline steel are ignored. The above research results cannot be applied to the heating-bending pipe of X100 pipeline steel. Some problems should be solved so that the security of X100 high-pressure pipelines can be ensured. The ductile damage of X100 steel should be evaluated for the accurate characterization of its ductile damage behavior at high temperatures.

In this study, a constitutive model integrating ductile damage of X100 pipeline steel is provided for the characterization of ductile damage behavior [18]. The model is based on the JC model. Some mechanical tests are conducted, and the relationship between triaxiality factor, high-temperature deformation, large strain rate, and ductile fracture resistance of pipeline steel is determined through a numerical study.

The remainder of this study is organized as follows: Section 3 describes the SHPB damage mechanics, Gleeble high-temperature mechanical, and quasi-static tensile tests and the JC damage constitutive model construction method. Section 4 investigates the flow stress and failure strain of X100 pipeline steel based on experimental data and verifies the accuracy and reliability of the damage constitutive model of X100 pipeline steel. Section 5 summarizes the conclusions.

\section{Methodology}

In this study, dual-phase ferrite (F) and bainite (GB) X100 pipeline steel were used as research objects. The main chemical compositions are shown in Table 1.

The X100 pipeline steel structure shown in Fig. 1 is a mixed structure of polygonal ferrite $(\mathrm{QF})$ and granular bainite (GB). Quasi-polygonal ferrite is irregular in shape, and its boundary is serrated or wavy. A gray etched area can be observed on the quasi-polygonal ferrite, which is an M-A component.

Table 1 Nominal chemical composition (weight \%)

\begin{tabular}{l|l|l|l|l|l|l|l|l}
\hline $\mathbf{C}$ & $\mathbf{S i}$ & $\mathbf{M n}$ & $\mathbf{C r}$ & $\mathbf{M o}$ & $\mathbf{N i}$ & $\mathbf{A l}$ & $\mathbf{C o}$ & $\mathbf{C u}$ \\
\hline 0.066 & 0.250 & 1.86 & 0.258 & 0.232 & 0.151 & 0.0332 & 0.0033 & 0.0295 \\
\hline $\mathbf{N b}$ & $\mathbf{T i}$ & $\mathbf{V}$ & $\mathbf{S n}$ & $\mathbf{A s}$ & $\mathbf{S b}$ & $\mathbf{B i}$ & $\mathbf{C a}$ & $\mathbf{S e}$ \\
\hline 0.0774 & 0.0142 & 0.0042 & 0.0021 & 0.0083 & 0.0128 & 0.0043 & 0.0026 & 0.0034 \\
\hline
\end{tabular}

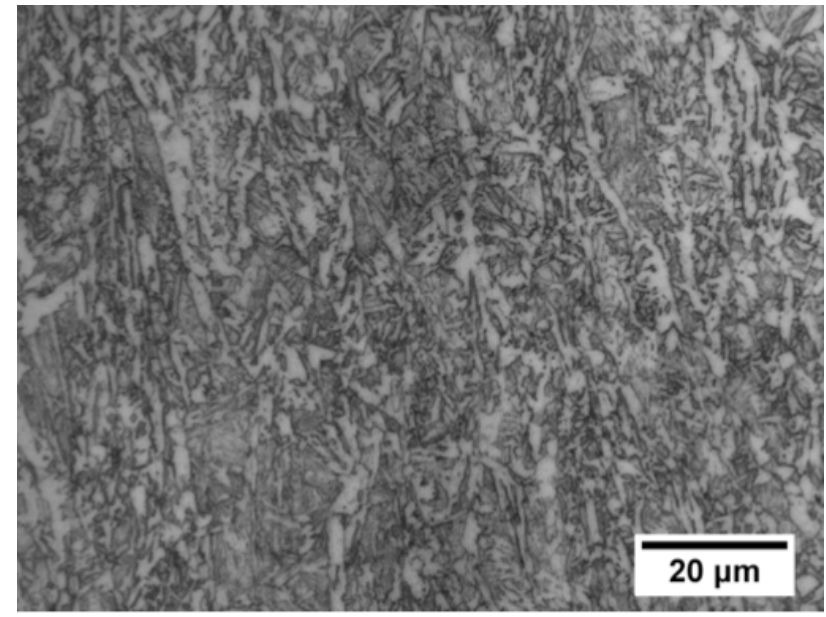

Fig. 1. Microstructure of X100

\subsection{Gleeble tensile test}

High-temperature plasticity experiments were conducted on $\mathrm{X} 100$ pipeline steel at different temperatures $\left(20^{\circ} \mathrm{C}, 800\right.$ $\left.1100{ }^{\circ} \mathrm{C}\right)$ and different strain rates $(0.001 / \mathrm{s}-10 / \mathrm{s})$ with a Gleeble-3800 thermal simulator. The stress-strain relationship of $\mathrm{X} 100$ pipeline steel at room temperature (20 $\left.{ }^{\circ} \mathrm{C}\right)$ and high strain rate $\left(10^{3}{ }^{\circ} \mathrm{C}-3 \times 10^{3} / \mathrm{s}\right)$ was measured through SHPB. The failure behavior of X100 pipeline steel was evaluated at room temperature through quasi-static tensile test $\left(20^{\circ} \mathrm{C}, 0.001 \mathrm{~s}\right)$.

Deformation behavior at high and room temperatures were determined by performing tensile tests on smooth round bar specimens. A Gleeble testing machine was used for the tensile tests at different strain rates $(0.001,0.01,0.1$, and $10 / \mathrm{s}$ ). The specimens used for tensile tests are shown in Fig. 2. 


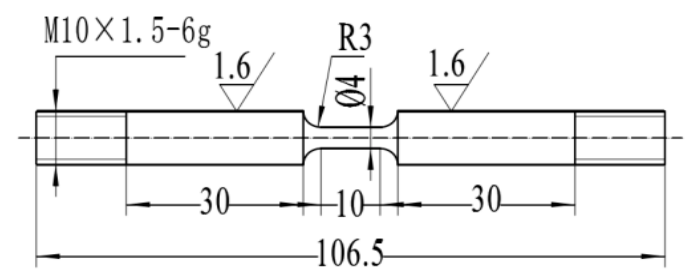

Fig. 2. Smooth round bar specimens (1).

The experimental data are processed by using Equation

$$
\left\{\begin{array}{l}
\sigma_{t}=\frac{F}{A} \\
\varepsilon_{t}=\operatorname{Ln}\left(\frac{A_{0}}{A}\right)
\end{array}\right.
$$

Where $F, A$, and $A_{0}$ are the current tensile load, current cross-section, and initial cross-section of the specimen, respectively.

Given that X100 pipeline steel has no obvious yield platform, the specified nonproportional extension strength was used for determining the yield strength of pipeline steel. Thus, the relationship between plastic strain and true strain was expressed as:

$\varepsilon_{p}=\varepsilon_{t}-\frac{\sigma_{t}}{E}-0.002$

On the basis of the proposed experimental methodology, the cross-section perimeter can be approximated with an ellipse, where $a$ and $b$ are the current semiaxes, identifying the reference coordinate system. Failure strain $\varepsilon_{f}$ can be calculated by using the following equation:

$$
\left\{\begin{array}{l}
\varepsilon_{f}=\operatorname{Ln} \frac{l}{l_{0}}=\operatorname{Ln} \frac{A_{0}}{A} \\
\varepsilon_{f}=\operatorname{Ln} \frac{d_{0}^{2}}{a b}
\end{array}\right.
$$

where $l, l_{0}$, and $d_{0}$ in Eq. (3) are the current tensile load, current cross-section, and initial undeformed crosssection of the specimen, respectively.

\subsection{SHPB test}

The dynamic mechanical properties of a material at strain rate of $10^{2}-10^{4} / \mathrm{s}$ are usually investigated through SHPB technique. The specimens were used for SHPB tensile tests (Fig. 3).

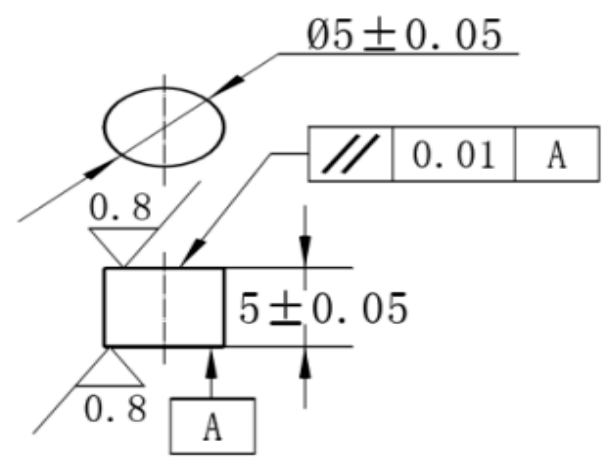

A "two-wave method" formula for solving the stressstrain relationship of stress wave was expressed as follows:

$\left\{\begin{array}{l}\dot{\varepsilon}=\frac{2 C_{0}}{L_{S}} \varepsilon_{r}(t) \\ \varepsilon_{e n}=\frac{2 C_{0}}{L_{S}} \int_{0}^{t} \varepsilon_{r}(t) d t \\ \sigma_{e n}=\frac{E_{0} d_{0}}{d_{S}} \varepsilon_{t}(t)\end{array}\right.$

where $\dot{\varepsilon}, \sigma_{e n}, \varepsilon_{e n}, L_{S}, \varepsilon_{r}(t), \varepsilon_{i}(t)$, and $\varepsilon_{t}(t)$ in Eq. (4) are the strain rate, engineering stress, engineering strain, reflector strain, incident bar strain, and transmission bar strain, respectively. The elastic modulus of the pressure bar is $E_{0}=1.9 \times 10^{5} \mathrm{MPa}$, the cross-sectional diameter of the press bar $\left(d_{0}\right)$ is $13 \mathrm{~mm}$, and the initial cross-sectional diameter of the specimen $\left(d_{s}\right)$ is $5 \mathrm{~mm}$.

Engineering stress $\sigma_{e n}$-engineering strain $\varepsilon_{e n}$ is converted into true stress-true strain relationship by using the following equation:

$\left\{\begin{array}{l}\varepsilon_{t}=-\ln \left(1-\varepsilon_{e n}\right) \\ \sigma_{t}=\sigma_{e n}\left(1-\varepsilon_{e n}\right)\end{array}\right.$.

At room temperature $\left(20^{\circ} \mathrm{C}\right)$, five strain rates, namely, 1000/s, 1500/s, 2000/s, 2500/s, and 3000/s, were used.

\subsection{Notched tensile test}

Notched tensile strength is a complicated mechanical phenomenon, in which the influence of stress state is prominent. The effects of stress triaxiality on the damage parameters of X100 pipeline steel were investigated on a notched round bar specimen through tensile test. The stress triaxiality of the specimen in uniaxial tensile test constantly changes, and the initial value of the specimen at the beginning of the drawing is generally selected to replace the stress triaxiality in the entire experiment. The initial stress triaxiality of the notch was estimated by using Bridgman's formula in Table 2.

$\frac{\bar{\sigma}_{m}}{\sigma_{e}}=\frac{1}{3}+\ln \left(1+\frac{a}{4 R}\right)$

where $\bar{\sigma}_{m}, \sigma_{e}, a$, and $R$ in Eq. (6) are the hydrostatic pressure $(\mathrm{MPa})$, equivalent stress $(\mathrm{MPa})$, smallest diameter of the notched part in the specimen $(\mathrm{mm})$, and gap radius of the specimen.

A quasi-static tensile test was conducted on a round bar specimen with notch radii of $1,1.5,3$, and $6 \mathrm{~mm}$ (Fig. 4a) and a smooth specimen without a notch (Fig. 4b) with an MTS electronic universal testing machine.

\subsection{JC model}

The damage evolution law of X100 pipeline steel was investigated for the accurate description of its damage behavior. The damage evolution model of X100 pipeline steel was constructed on the basis of the JC model. The JC

Fig. 3. SHPB specimens 
model includes flow stress equations (Equation 7) and damage failure model (Equation 8).

$$
\sigma=\left(A+B \varepsilon^{n}\right)\left(1+C \ln \frac{\dot{\varepsilon}}{\dot{\varepsilon}_{0}}\right)\left(1-T^{* m}\right)
$$

where $\dot{\varepsilon}_{0}$ is the reference strain rate $\left(\mathrm{s}^{-1}\right)$, which is $0.001 / \mathrm{s}$ in this study; $T^{*}$ denotes the dimensionless temperature relative value; and $T^{*}=\left(T-T_{r}\right) /\left(T_{m}-T\right)_{r}$, where $T$ is the test temperature, $T_{\mathrm{r}}$ is the room temperature $\left(20^{\circ} \mathrm{C}\right), T_{\mathrm{m}}$ is the melting point of the material $\left(1425^{\circ} \mathrm{C}\right)$, and $A, B, n, C$, and $m$ are the equation parameters.

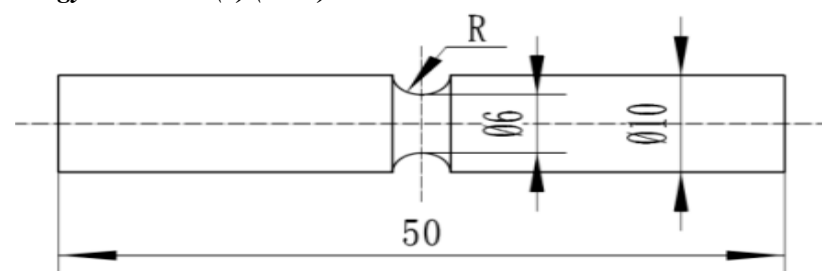

(a) Notch specimen

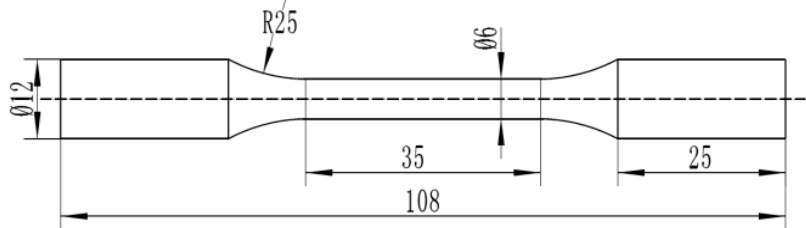

(b) Smooth specimen

Fig. 4. Quasi-static tensile test of specimens

Table 2 Specimen dimensions and triaxial stress

\begin{tabular}{c|c|c|c}
\hline Gap radius $\boldsymbol{R}(\mathbf{m m})$ & Smallest diameter $\boldsymbol{a}(\mathbf{m m})$ & Maximum radius $\boldsymbol{D}(\mathbf{m m})$ & Initial stress triaxiality \\
\hline 1 & 6 & 10 & 1.250 \\
1.5 & 6 & 10 & 1.026 \\
3 & 6 & 10 & 0.739 \\
6 & 6 & 10 & 0.556 \\
Smooth $(\infty)$ & 6 & 12 & 0.333 \\
\hline
\end{tabular}

$\varepsilon_{f}=\left[D_{1}+D_{2} \exp \left(D_{3} \frac{\bar{\sigma}_{m}}{\sigma_{e}}\right)\right]\left(1+D_{4} \ln \frac{\dot{\varepsilon}}{\dot{\varepsilon}_{0}}\right)\left(1+D_{5} T^{*}\right)$

where $D_{1}-D_{5}$ denote the failure criterion parameter.

A nonlinear least squares optimization algorithm was used for the determination of the model parameters on the basis of experimental data. The optimization model of flow stress equation parameters was expressed as follows:

$$
\left\{\begin{array}{l}
\boldsymbol{x}_{1}=(A, B, n, C, m)^{\mathrm{T}} \\
\min : F_{1}(\boldsymbol{x})=\sum_{i=1}^{n} f_{1 i}(\boldsymbol{x})^{2}=\sum_{i=1}^{n}\left[\sigma_{i}(\boldsymbol{x})-\sigma_{0}(i)\right]^{2}
\end{array}\right.
$$

The optimization model of damage failure was expressed as follows:

$$
\left\{\begin{array}{l}
\boldsymbol{x}_{2}=\left(D_{1}, D_{2}, D_{3}, D_{4}, D_{5}\right)^{\mathrm{T}} \\
\min : F_{2}(\boldsymbol{x})=\sum_{i=1}^{m} f_{2 i}(\boldsymbol{x})^{2}=\sum_{i=1}^{m}\left[\varepsilon_{f i}(\boldsymbol{x})-\varepsilon_{f 0}(i)\right]^{2}
\end{array}\right.
$$

The X100 damage constitutive model was transplanted into the ABAQUS/Explicit module. The model of Gleeble high-temperature tensile test, room-temperature SHPB experiment, and finite element analysis model of notched tensile test were established. The specimen structure and boundary conditions were axisymmetric, and a 2D axisymmetric model was established for the simulation.

Damage variables $D$ are measured based on the criterion of plastic strain accumulation:

$$
D=\sum \frac{\Delta \varepsilon_{p}}{\varepsilon_{f}}
$$

increment, $D$ is the damage parameter of the material, and the material is destroyed when $D=1$.

\section{Result Analysis and Discussion}

\subsection{Experiment Result Analysis}

The curves of true stress-plastic strain at room and high temperatures are shown in Figs. 5 and 6, respectively.

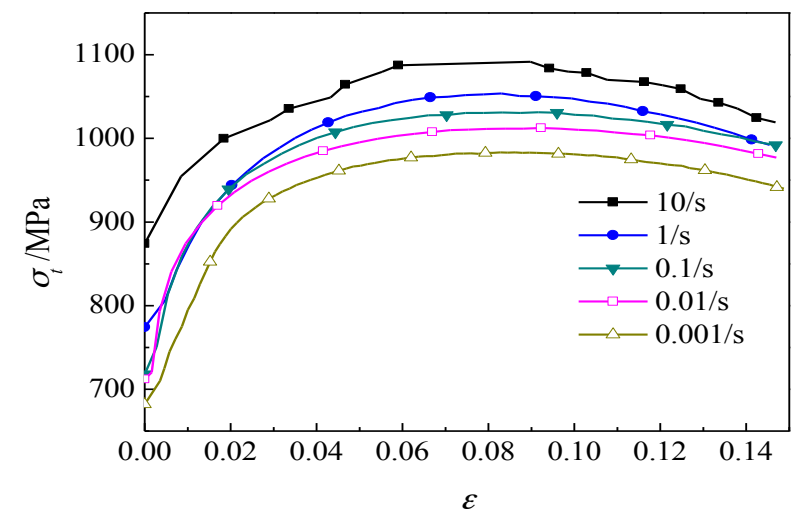

Fig. 5. Curves of true stress-plastic strain at room temperature

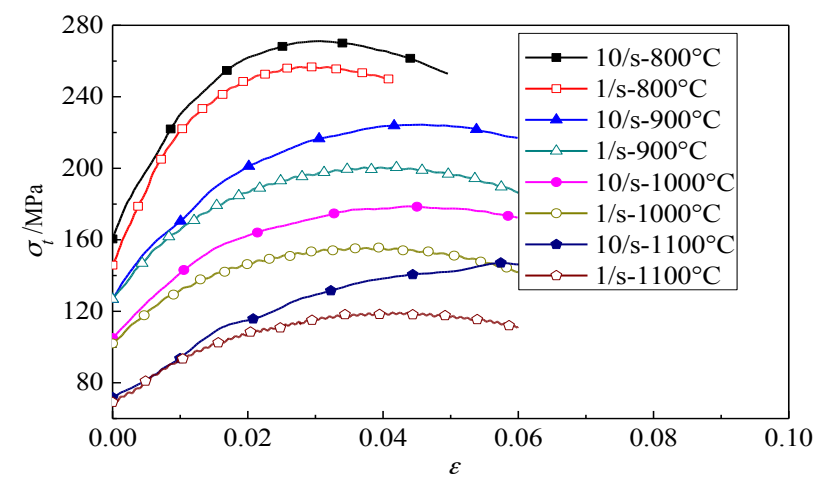

Fig. 6. Curves of true stress-plastic strain at high temperature 


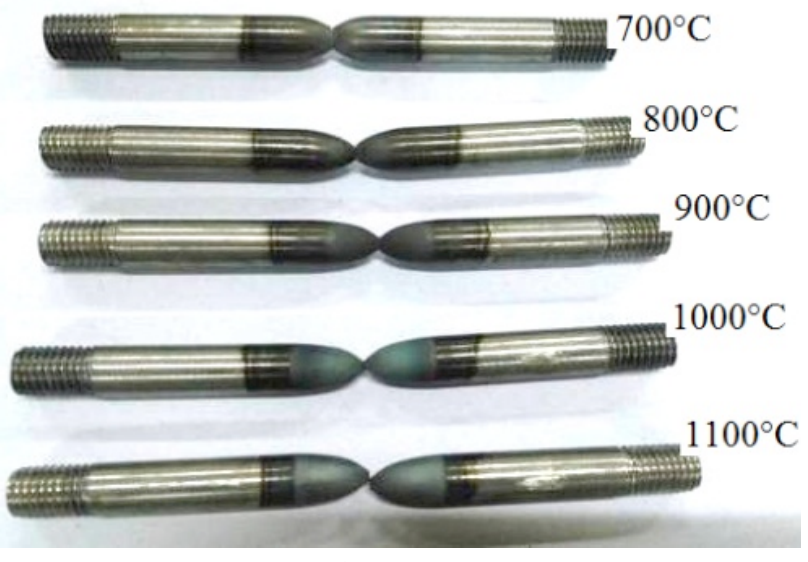

(a) $\dot{\varepsilon}_{1}=1 / \mathrm{s}$

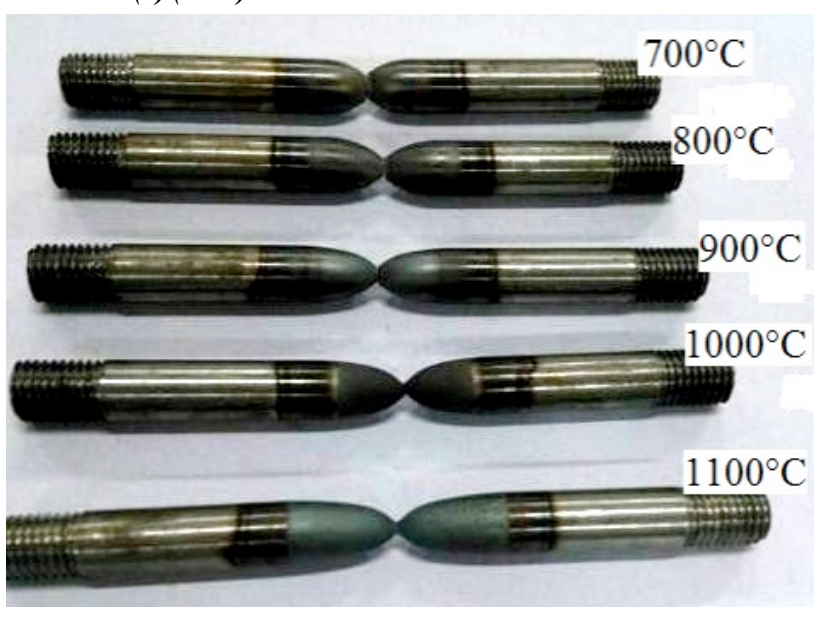

(b) $\dot{\varepsilon}_{2}=10 / \mathrm{s}$

Fig. 7. Specimens at different temperatures and strain rates after fracture

Table 3 Mechanical properties obtained from the tensile test

\begin{tabular}{|c|c|c|c|c|c|}
\hline & $\begin{array}{c}\text { Temperature } \\
\left({ }^{\circ} \mathrm{C}\right)\end{array}$ & $\begin{array}{c}\text { Strain rate } \\
\left(\mathrm{s}^{-1}\right)\end{array}$ & $\begin{array}{l}\text { Yield strength } \\
(\mathrm{MPa})\end{array}$ & $\begin{array}{l}\text { Ultimate tensile } \\
\text { strength (MPa) }\end{array}$ & $\begin{array}{l}\text { Failure } \\
\text { strain }\end{array}$ \\
\hline \multirow{5}{*}{ Room temperature } & \multirow{5}{*}{20} & $10^{-3}$ & 682 & 983 & 1.722 \\
\hline & & $10^{-2}$ & 712 & 1012 & 1.561 \\
\hline & & $10^{-1}$ & 718 & 1031 & 1.584 \\
\hline & & 1 & 774 & 1054 & 1.399 \\
\hline & & 10 & 874 & 1092 & 1.214 \\
\hline \multirow{8}{*}{ High temperature } & \multirow{2}{*}{800} & 1 & 146 & 257 & 2.248 \\
\hline & & 10 & 160 & 271 & 2.163 \\
\hline & \multirow{2}{*}{900} & 1 & 126 & 201 & 2.628 \\
\hline & & 10 & 127 & 224 & 2.567 \\
\hline & \multirow{2}{*}{1000} & 1 & 102 & 155 & 3.7 \\
\hline & & 10 & 105 & 179 & 3.164 \\
\hline & \multirow{2}{*}{1100} & 1 & 69 & 119 & 3.766 \\
\hline & & 10 & 72 & 147 & 3.758 \\
\hline
\end{tabular}

For the curves of the true stress-plastic strain, hardening and failure behavior can be identified from the experimental data in Table 3. Thus, the hardening and failure behavior were summarized as follows:

(1) The strain hardening effect was significant when it entered the plastic stage because the true stress-plastic strain curve was obviously convex. The true stress increased with the strain rate under the same conditions, and the yield and ultimate tensile strengths of the X100 pipeline steel increased by $28.2 \%$ and $11.1 \%$, respectively, when the strain rate increased from $10^{-3} / \mathrm{s}$ to $10 / \mathrm{s}$ at room temperature. Meanwhile, the yield and ultimate tensile strengths increased by $4.3 \%$ and $23.5 \%$, respectively, when the strain rate increased from $1 / \mathrm{s}$ to $10 / \mathrm{s}$ at $1100{ }^{\circ} \mathrm{C}$. Thus, they played a role in strengthening the strain rate on the flow stress of $\mathrm{X} 100$ pipeline.

(2) The true stress-plastic strain curve at increasing temperature tended to decline from the test data in Table 1. The yield strength from $20{ }^{\circ} \mathrm{C}$ to $1100{ }^{\circ} \mathrm{C}$ decreased by $91.8 \%$, and the ultimate tensile strength reduced by $86.5 \%$ at strain rate of $10 / \mathrm{s}$. Hence, the temperature softening effect was extremely significant.

(3) The effects of temperature and strain rate on the cross-section of the material after breakage were obvious.

(4) The failure strain decreased with increasing strain rate and increased with temperature.

The true stress-true strain curve sharply increased and decreased when the X100 pipeline steel entered the plastic deformation state, as shown in Fig. 8. Thus, X100 pipeline steel during thermal deformation was accompanied with recovery and recrystallization and partly counteracted the work hardening effect.

As shown in Fig. 9, the deformation of the notched specimen was smaller than that of the smooth specimen, and the gap of notched specimen was focused on major deformation during the tensile process. The fracture displacement decreased with increasing stress triaxiality. The effects of stress triaxiality on maximum load, section shrinkage, and failure strain were obtained through the notched tensile test.

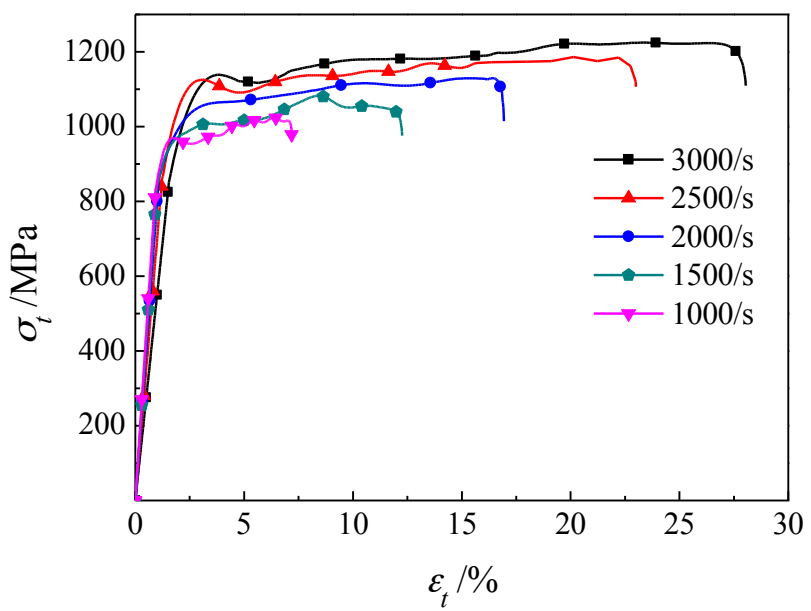

Fig. 8. SHPB true stress-true strain curve

As shown in Fig. 10, the maximum load increased with stress triaxiality, and thus increase in stress triaxiality can 
improve the deformation resistance of the material. Meanwhile, the fracture area increased with stress triaxiality, whereas failure strain decreased, as shown in Figs. 11-12. The specimen with a notch radius of $1 \mathrm{~mm}$ decreased by $41.4 \%$ compared with the smooth specimen, and the failure strain was reduced by $57.8 \%$. This result indicates that the effect of stress state on material damage failure is significant.

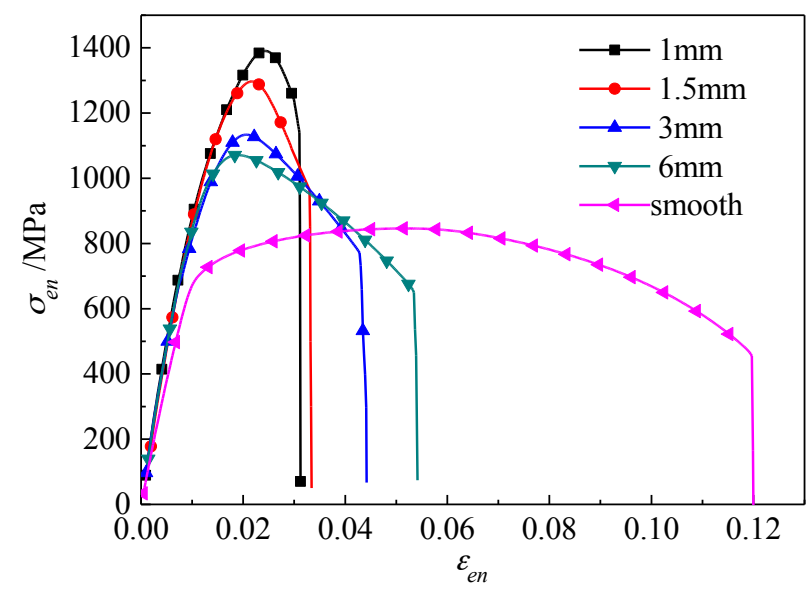

Fig. 9. Stress-strain curve of notched round bar specimens

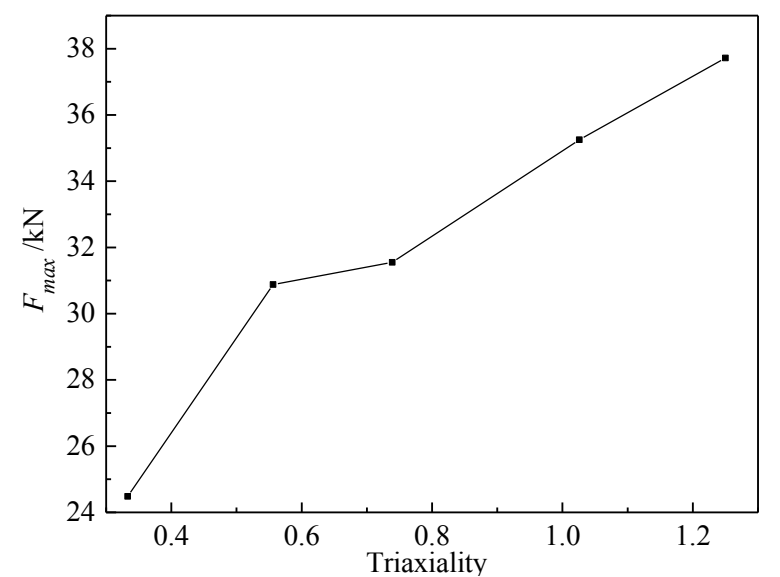

Fig. 10. Relationship between maximum load and stress triaxiality

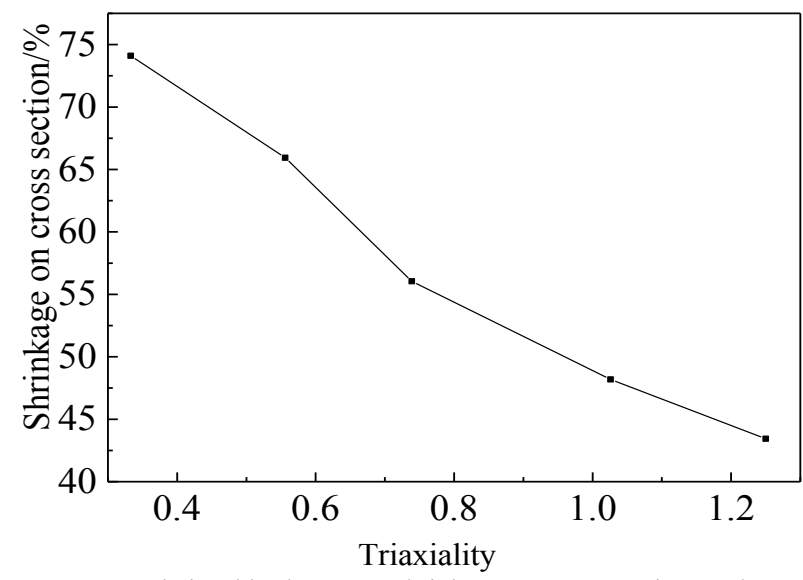

triaxiality

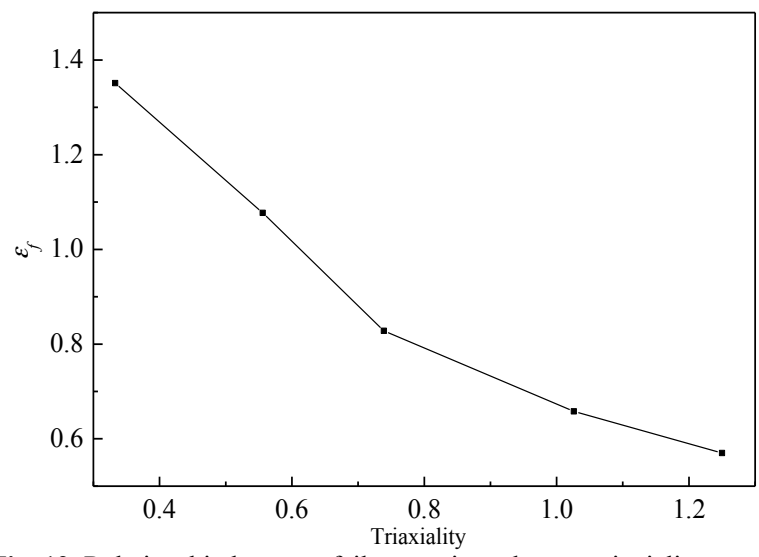

Fig. 12. Relationship between failure strain and stress triaxiality

\subsection{Constitutive model establishment}

The iterative calculation of the above optimization model was conducted on MATLAB. The model parameters are shown in Table 4.

The JC model of X100 pipeline steel was analyzed and calculated on ABAQUS/Explicit. The reliability of JC flow stress equation of the X100 pipeline steel was verified by establishing the finite element analysis model of the tensile test at high temperatures and SHPB test. Thus, the simulated and experimental results of stress-strain relationship were compared.

The stress and strain curves of the simulation are in good agreement with the test in Fig. 13. The JC flow stress equation had a large error at low temperatures, in which the maximum absolute error of yield up to $8 \mathrm{MPa}$ was approximately $8.6 \%$, and the maximum absolute error of tensile strength of up to $16 \mathrm{MPa}$ was approximately $7.3 \%$.

The simulation of SHPB true stress-true strain curve agreed well with the experimental results in Fig. 14, and the maximum error was $2.4 \%$. The results demonstrated the reliability and accuracy of the JC flow stress equation at high strain rates.

The finite element analysis model of notched tensile test was established to verify the reliability of the JC failure model of X100 pipeline steel. In this study, The degree of damage in the material was evaluated with the plastic strain accumulation criterion.

$$
D=\sum \frac{\Delta \varepsilon_{p}}{\varepsilon_{f}},
$$

where $\Delta \varepsilon_{p}$ is the equivalent plastic strain increment, and $D$ is the material damage parameter. The material was broken when $D=1$.

Fig. 11. Relationship between shrinkage on cross-section and stress

Table 4 JC model parameters

\begin{tabular}{|c|c|c|c|c|c|c|}
\hline \multirow{2}{*}{ Flow stress equation } & $A$ & $B$ & $n$ & $C$ & $m$ & $F_{1}$ \\
\hline & 687.6097 & 495.5723 & 0.3277 & 0.0155 & 0.4106 & $6.003 \times 104$ \\
\hline \multirow{2}{*}{ Damage failure } & $D_{1}$ & $D_{2}$ & $D_{3}$ & $D_{4}$ & $D_{5}$ & $F_{2}$ \\
\hline & 0.4846 & 2.6379 & -2.7102 & -0.0259 & 2.1439 & 1.9977 \\
\hline
\end{tabular}


Lifeng Fan, Ge Wang, Pei Liang, Jing Ma, Qunqun Bao and Hong Zhang/

Journal of Engineering Science and Technology Review 12 (2) (2019) 161 - 169

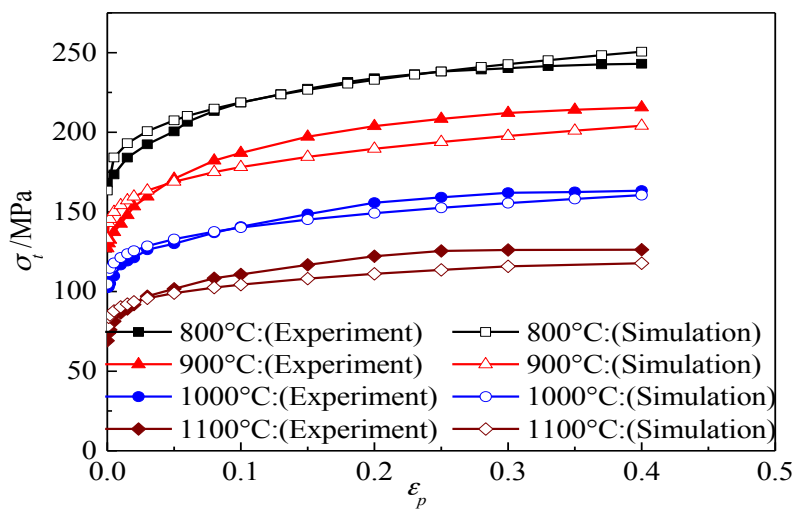

a) $\dot{\varepsilon}_{1}=1 / \mathrm{s}$

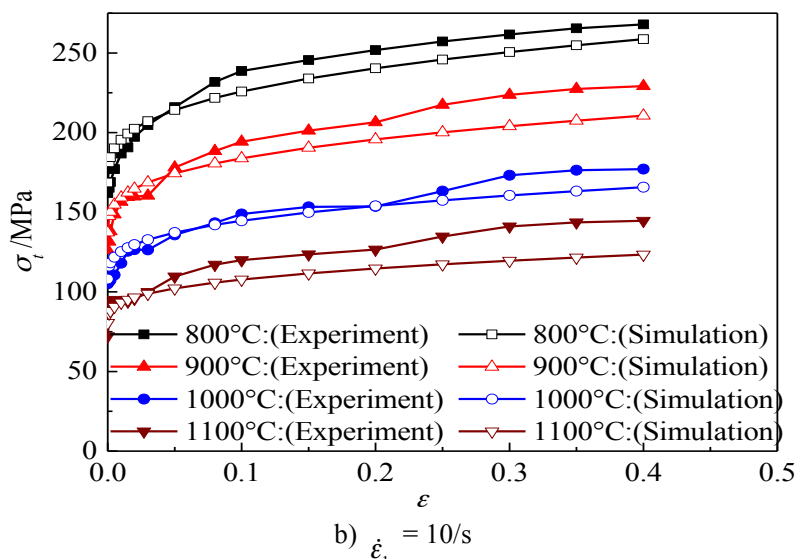

Fig. 13. Relationship between failure strain and stress triaxiality

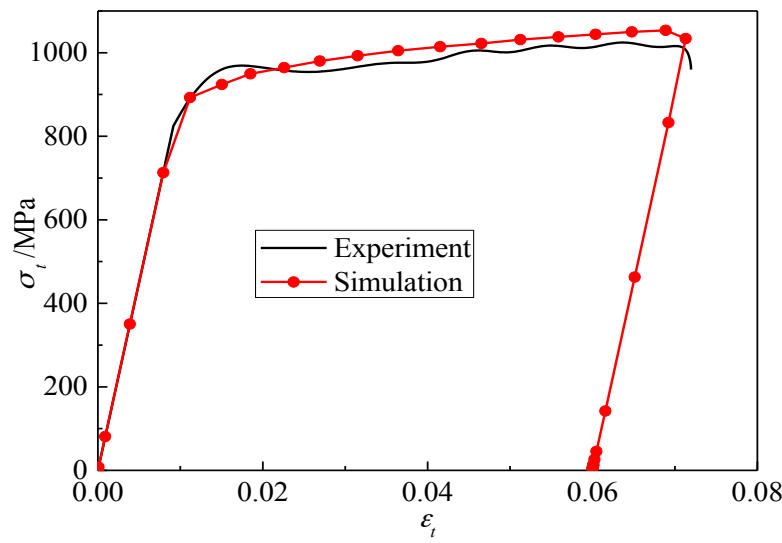

a) $\dot{\varepsilon}_{1}=1000 / \mathrm{s}$

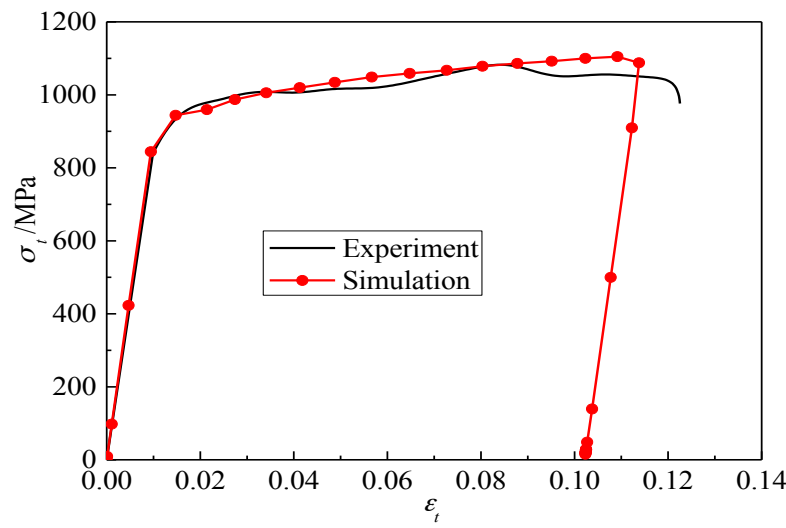

b) $\dot{\varepsilon}_{1}=1500 / \mathrm{s}$

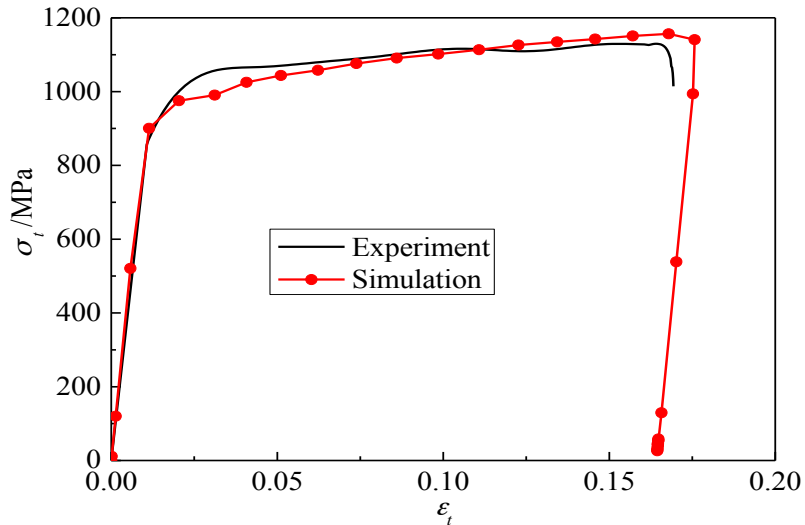

c) $\dot{\varepsilon}_{1}=2000 / \mathrm{s}$

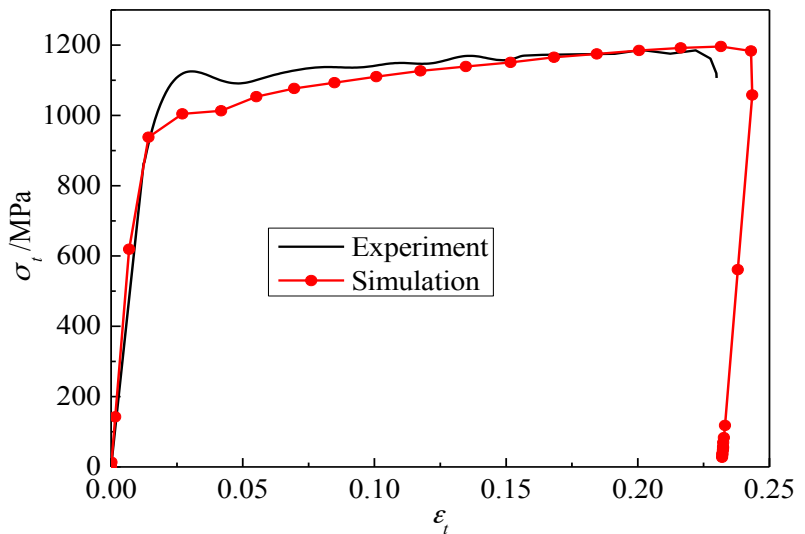

d) $\dot{\varepsilon}_{1}=2500 / \mathrm{s}$

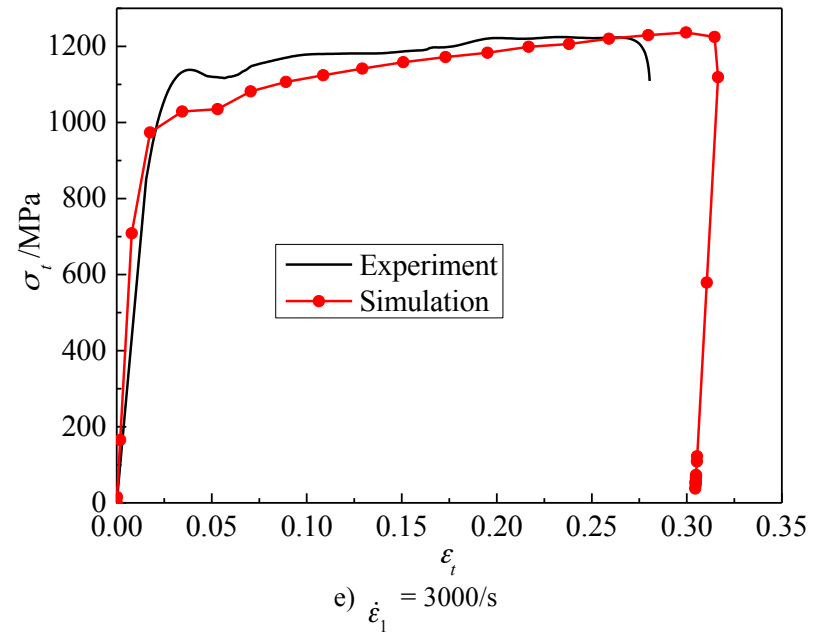

Fig. 14. Simulation of SHPB true stress-true strain curve

The accuracy of JC failure criterion was verified by comparing the tensile displacement and test results when JCCRT was equal to 1 . As shown in Table 7, the simulated fracture displacement coincided with the experimental fracture displacement, and the maximum absolute error was $0.073 \mathrm{~mm}$.

Table 5 Fracture displacement $(\mathrm{mm})$

\begin{tabular}{c|c|c|c}
\hline $\begin{array}{c}\text { Notch } \\
\text { radius } \boldsymbol{R}\end{array}$ & $\begin{array}{c}\text { Experiment } \\
\text { value }\end{array}$ & $\begin{array}{c}\text { Simulation } \\
\text { value }\end{array}$ & Error \\
\hline 1 & 1.614 & 1.61 & 0.004 \\
1.5 & 1.655 & 1.63 & 0.025 \\
3 & 2.162 & 2.15 & 0.012 \\
6 & 2.673 & 2.60 & 0.073 \\
\hline
\end{tabular}


Lifeng Fan, Ge Wang, Pei Liang, Jing Ma, Qunqun Bao and Hong Zhang/

Journal of Engineering Science and Technology Review 12 (2) (2019) 161 - 169

The damage evolution law of deformation is analyzed under different stress triaxiality and cross-section conditions, as shown in Fig. 15. The field variable JCCRT in ABAQUS represents damage variable $D$. Fig. 15 shows the variations of JCCRT with stretching displacement. JCCRT curves are presented as exponential shape. A crack occurs in the first cross-sectional center.

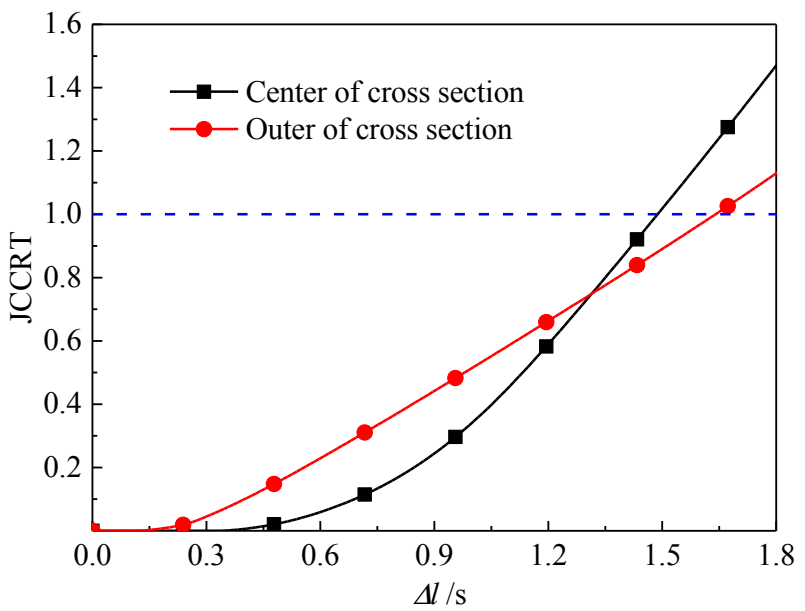

a) $R=1 \mathrm{~mm}$

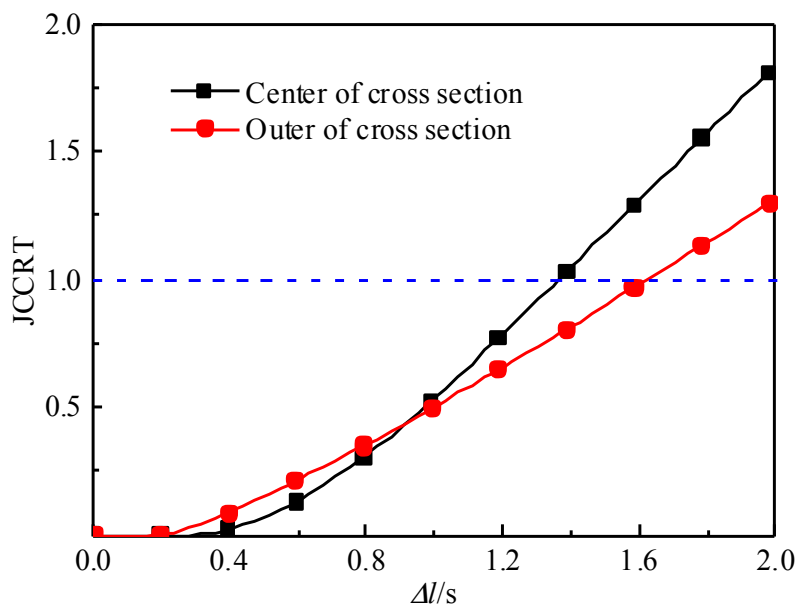

b) $R=1.5 \mathrm{~mm}$

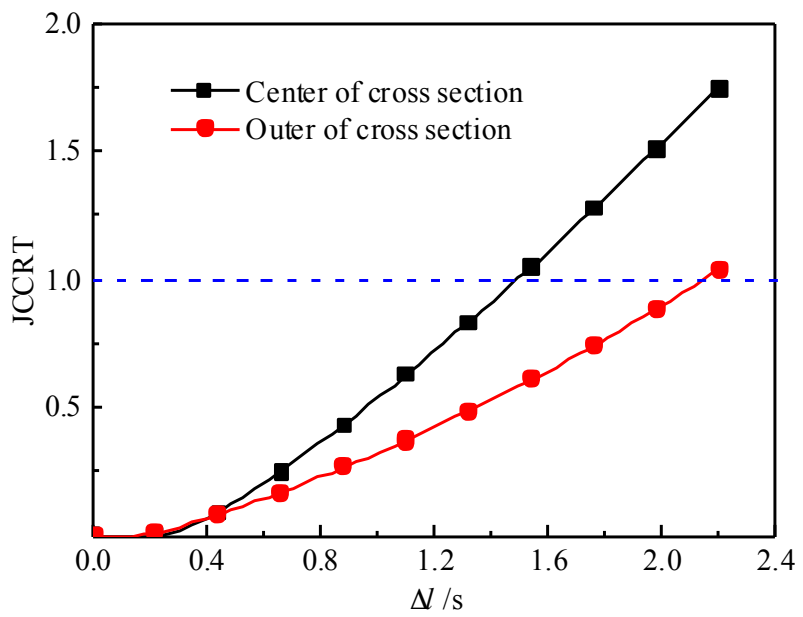

c) $R=3 \mathrm{~mm}$

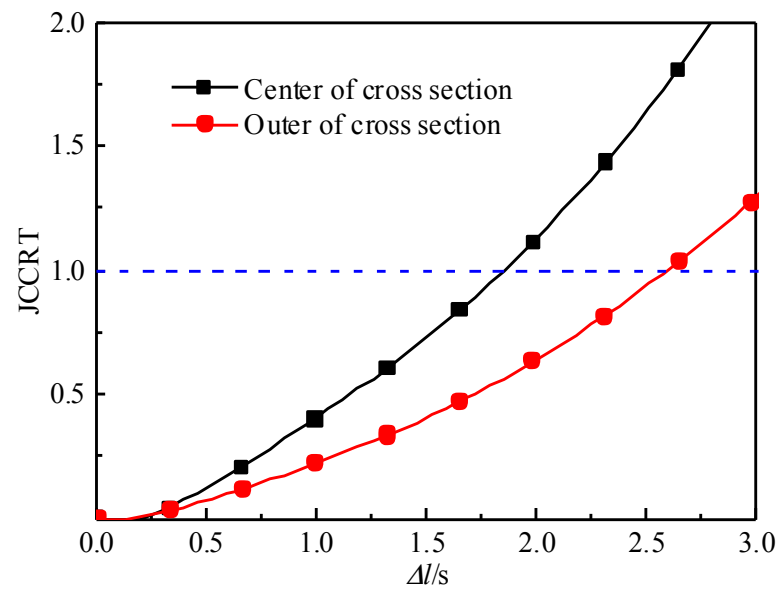

d) $R=6 \mathrm{~mm}$

Fig. 15. Damage variable $D$ is accumulated with stretching displacement

\section{Conclusions}

To reveal the high-temperature plastic damage fracture evolution of high strength pipeline steels, we discussed the effects of stress triaxiality, strain rate, and temperature on the plastic damage of X100 pipeline steel. The characteristics of flow stress and failure strain of the X100 pipeline steel were analyzed through Gleeble quasi-static and dynamic tensile, SHPB, and MTS quasi-static notch tensile tests at room and high temperatures. The damage constitutive model of X100 pipeline steel based on the JC model was established. The conclusions were as follows:

(1) The true stress-plastic strain curve of the X100 pipeline steel material increased with strain rate. Thus, the strain rate of X100 pipeline steel plastic flow stress may have played an important role in hardening.

(2) The true stress-plastic strain curve of X100 pipeline steel showed a decreasing trend with increasing temperature, and the softening effect of temperature was significant.

(3) The failure strain of X100 pipeline steel was positively correlated with temperature and negatively correlated with strain rate and stress triaxiality.

(4) The damage constitutive model of X100 pipeline steel can be used to describe the plastic deformation and damage evolution behavior of X100 pipeline steel at high temperatures.

This study investigated the high-temperature ductility and damage behavior of X100 pipeline steel through experiments. The proposed damage constitutive model of X100 pipeline steel was constructed based on the JC model, which can describe the high-temperature plastic deformation and damage evolution behavior of X100 pipeline steel.

The results can be used as a reference for optimizing the heating-bending technical parameters of pipes. However, the present study still has some shortcomings, such as the lack of research on the anisotropy of high-temperature plasticity and damage of X100 pipeline steel. In future studies, anisotropy will be considered in the modification of the constitutive model, which can accurately describe the behavior of a material during plastic deformation and damage evolution at high temperatures.

\section{Acknowledgements}

This work was supported by by the National Natural Science Foundation of China (51761030). 
Lifeng Fan, Ge Wang, Pei Liang, Jing Ma, Qunqun Bao and Hong Zhang/

Journal of Engineering Science and Technology Review 12 (2) (2019) 161 - 169

This is an Open Access article distributed under the terms of the

Creative Commons Attribution License

\section{References}

1. Duan L. N., Chen Y., Microstructures and Mechanical Properties of X100 Pipeline Steel Strip, Journal of Iron and Steel Research, 21(2), 2014, pp,227-232.

2. Maxey W. A., Kiefner J. F., Eiber R. J., Ductile fracture arrest in gas pipelines, American Gas Association, Arlington, VA, 1976. pp,127132.

3. Jian S., Hong Z., Yonggang W., Shiliang D, Research advance of dynamic crack propagation and arrest techniques for gas transmission pipeline, Shiyou Daxue Xuebao, 28(3), 2004, pp,129 135.

4. Oh C. K., Kim Y. J., Baek J. H. , Kim W. S., Development of stressmodified fracture strain for ductile failure of API X65 steel, Internation Journal of Fracture, (143), 2007, pp,119-133.

5. Qiu H. , Mori H. , Enoki M., Evaluation of ductile fracture of structural steels by microvoid model, ISIJ international, 39(4), 1999, pp,358-364.

6. Poruks P., Yakubtsov I., Boyd J. D., Martensite ferrite interface strength in a low-carbon bainitic steel, Scripta Materialia, 54(1), 2006, pp,41-45.

7. Baowen Q., "Research on Ductile Fracture of X80 Pipeline Steel and Finite Element Simulation". Doctoral Dissertation Wuhan University Of Technology, 2015. pp,121-125.

8. Luca C., Tommaso C., Flavia C., Prediction of ductile failure in materials for onshore and offshore pipeline applications, International Journal of Damage Mechanics, (23), 2014, pp,104123.

9. Akbari A. R., Jafari S. , Hosseinipour S. J., Experimental and numerical investigation of ductile damage effect on load bearing capacity of a dented API XB pipe subjected to internal pressure, Engineering Failure Analysis, (47), 2015, pp,208-228.
10. Kim N. H., Oh C. S. , Kim Y. J., Comparison of fracture strain based ductile failure simulation with experimental results, International Journal of Pressure Vessels and Piping, (88), 2012, pp,434-447.

11. Sebastian M, Ulrich P, Wolfgang B. Numerical modelling of toughness and failure processes in steel structures, Steel Research International. 2007, 3(78): 224-235.

12. Robert L. A., Elizabeth S. D., Fatigue Crack Growth Modeling of Pipeline Steels in High Pressure Gaseous Hydrogen, International Journal of Fatigue, (62), 2014, pp,249-257.

13. Rahmatollah G., Giuseppe M., Ductile failure of X100 pipeline steel-Experiments and fractography, Materials and Design, (43), 2013, pp,513-525.

14. Iob F., Campanelli F., Coppola T., Modelling of anisotropic hardening behavior for the fracture prediction in high strength steel line pipes, Engineering Fracture Mechanics, 11(143), 2015, pp,363-382.

15. Tanguya B., Luua T. T., Perrinb B. G., Plastic and damage behaviour of a high strength X100 pipeline steel: Experiments and modeling, International Journal of Pressure Vessels and Piping, (85), 2008, pp,322-335

16. Yang L., Weimin M., Lingkang J., The Effect of Constraint on Ductile Crack Growth for Anisotropy Evaluation of X100 Pipeline Steels, Procedia Materials Science, 3, 2014, pp,1505 -1511.

17. Mirone G., Corallo D., Stress-strain and ductile fracture characterization of an X100 anisotropic steel: Experiments and modeling, Engineering Fracture Mechanics, 102, 2013, pp, 118-145.

18. Johnson G. R., Cook W. H., Fracture Characteristics of Three Metals Subjected to Various Strains, Strain Rates, Temperatures and Pressures, Engineering Fracture Mechanics, 21, 1985, pp,3148. 